\title{
HUNIAN AWAL SEJARAH \\ DI PESISIR KAIMANA, PAPUA BARAT \\ (Early History of Setlement in Kaimana Coast, West Papua)
}

\author{
M. Irfan Mahmud \\ Balai Arkeologi Jayapura \\ irfanarkeologi@yahoo.co.id
}

\begin{abstract}
Coastal Kaimana be one important area to understand overview of the early history of civilization in New Guinea. Kaimana evolved since the empire archipelago use as a transit port as archaeological traces were found. A necessity, residential visited various ethnic groups in the past will also produce a diversity of artifacts. Instead, it is important to know two things from Kaimana coastal sites, namely: (i) the diversity of artifacts; and (ii) the character of the culture that developed in the residential area. Picture of two things is intended to show on the one hand, the contribution of the archipelago to the development of local communities in Papua early history, while on the other hand know the influence of external elements of the character of the local culture. By using a method known archaeological survey that multiculturalism has grown in residential site at Kaimana coast, where the infrastructure reflects the character of the maritime civilization open, advanced, and adaptive to the elements of the outer cover all aspects of life: social, economic, cultural, historical, to religion.
\end{abstract}

Keywords: Kaimana, settlement, cultural character, archaeology

\begin{abstract}
ABSTRAK
Pesisir Kaimana menjadi salah satu kawasan penting untuk memahami gambaran peradaban masa awal sejarah di Pulau Papua. Kaimana berkembang sejak imperium Nusantara menggunakan sebagai pelabuhan transit sebagaimana jejak arkeologi yang ditemukan. Suatu keniscayaan, hunian yang dikunjungi berbagai etnis di masa lalu juga akan menghasilkan keragaman artefak. Justru itu, penting untuk mengetahui dua hal dari situs pesisir Kaimana, yaitu: (i) keragaman artefak; dan (ii) karakter budaya yang berkembang di dalam kawasan hunian. Gambaran dua hal tersebut ditujukan untuk memperlihatkan pada satu pihak kontribusi Nusantara terhadap perkembangan komunitas lokal Papua masa awal sejarah, sementara dilain pihak mengatahui pengaruh anasir luar terhadap karakter budaya setempat. Dengan menggunakan metode survei arkeologi diketahui bahwa multikulturalisme telah berkembang pada situs hunian di pesisir Kaimana, dimana infrastrukturnya mencerminkan karakter peradaban maritim yang terbuka, maju, dan adaptif dengan anasir dari luar melingkupi segala aspek kehidupan: sosial, ekonomi, budaya, sejarah, hingga religi.
\end{abstract}

Kata kunci: Kaimana, hunian, karakter budaya, arkeologi

Tanggal masuk : 15 September 2014

Tanggal diterima : 3 November 2014 


\section{PENDAHULUAN}

Kaimana merupakan salah satu petuanan (kerajaan) di bagian selatan wilayah Kepala Burung, Papua. Wilayah petuanan di pesisir Kaimana, sekarang dihuni masyarakat multikultur, berasal dari beragam etnis dan agama. Kisahkisah yang terus bergaung sangat mengandung semangat persaudaraan, meskipun berbeda etnis dan agama mereka hidup berdampingan dengan sangat toleran dan bekerja menurut kemampuannya. Penduduk asli bekerja sebagai nelayan, pedagang atau petani pala, salak, serta kelapa. Komunitas Cina di kota Kaimana lebih mendominasi kepemilikan pertokoan dan pusat perbelanjaan, sedangkan orang Jawa, Madura, Bugis, Makassar mendominasi usaha di pasar rakyat, warung makan serta jual-beli di teras pertokoan dari sore hingga larut malam.

Dahulu Kaimana menjadi tempat sandar perahu-perahu saudagar Maluku memasuki sumber komoditas hutan di pedalaman sambil memperdagangkan atau menukarkan barang dagangan luar. Pada pelabuhan alam yang tumbuh sebagai sumbu pertukaran, kemudian terus menerangi lahirnya kelompok hunian komunitas yang terpencar di pesisir Tanjung Bicari, Kaimana ${ }^{1}$. Yang pantas diamati bukan hanya kota Kaimana sekarang, beberapa pulau di sekitarnya juga mencerminkan situs hunian awal sejarah yang mula-mula dipilih lebih

1 Berdasarkan bahasa yang digunakan, kawasan Kaimana sampai sekarang didiami oleh sembilan suku asli (indigenious people), yaitu: (1) Suku Baham, menghuni Kampung Sanggrung dan Weri; (2) Suku Irarutu, menghuni Kampung Fruta, Naramas, Wagura, Afuafu, Gusimawa, Boywer, dan Nagura; (3) Suku Kamberau menghuni Kampung Inan, Wania, Ubia Seramuku, Kukasa, Tanggaromi, Coa, dan Krooy; (4) Suku Mairasi, menghuni Kampung Barari, Morano, Maimai, Lobo dan Sisir sampai Teluk Wondama; (5) Suku Biruai menghuni Kampung Guriasa, Hia, dan Yarona; (6) Suku Koiwai, menghuni Kaimana Kota, Namatota, dan Adi Jaya; (7) Suku Semimi, menghuni Kampung Nanesa, Kampung Kayu Merah yang berbatasan langsung dengan Suku Kamoro; (8) Suku Karas, menghuni Pulau Karas; dan (9) Suku Uruangniri yang mengokupasi pulau-pulau kecil di belakang Pulau Karas yaitu Kampung Tumbawaga. karena pertimbangan kemudahan mengontrol lingkungan dan posisi strategisnya sebagai tempat transit untuk menerobos belantara memasuki sumber komoditas hutan.

Pada awal masa sejarah, hunian di pesisir dan pulau-pulau Kaimana kemudian berkembang menjadi petuanan yang mengendalikan sistem sosial-ekonomi dibawah perlindungan dinasti Maluku. Penguasa baru yang lahir di hunian pesisir Kaimana, dengan cepat mengintrodusir unsur-unsur peradaban dari luar yang semakin memapankan posisi sosialnya. Para penguasa baru di pesisir Kaimana menjalankan moraletik agama baru dan menganyomi tatanan budaya tradisional dengan warna baru. Meluasnya pengaruh dinasti Islam lebih dari lima abad lalu, salah satu diantaranya, memberi warna baru dalam keterhubungan antara Kepulauan Maluku dan Papua. Jika sebelumnya kontak antar kedua wilayah cenderung didominasi aspek pertukaran dan perdagangan semata, maka dengan munculnya kerajaankerajaan Islam di Maluku Utara memberi nuansa ideologi dan politik dalam interaksi antar kedua kawasan.

Dalam konteks ini jaringan perdagangan jarak-jauh yang telah mapan terbentuk sejak awal masehi menjadi medium yang efektif dalam proses introduksi Islam hingga ke bagian selatan Kepulauan Maluku dan pesisir barat Papua, sampai menjangkau Kaimana sebagai batas terjauh ke timur di pesisir selatan. Keberadaan Islam di Kepulauan Maluku dan Papua sejatinya juga membentuk batas terluar pengaruh Islam di ujung timur Kepulauan Asia Tenggara. Implikasi material untuk batas-batas terluar geografi Islam ini kiranya masih potensial untuk ditinjau lebih dalam, termasuk bentuk-bentuk variasi lokal dalam kawasan tersebut (Ririmase, 2011). 
Sentuhan peradaban juga diinisiasi komunitas Cina yang bermigrasi ke Nusantara jauh sebelum kedatangan Belanda (Onghokham, 2008:1). Di Papua keberadaan komunitas Cina yang membentuk perkampungan eksklusif selain terdapat di Yapen dan Pulau Roon (Sorong), juga ditemukan di pesisir Kaimana, Papua Barat. Keberadaan komunitas Cina di Papua terpola oleh sebuah rangkaian migrasi yang saling sambung menyambung; mereka yang ada di setiap daerah kepulauan di Nusantara melakukan proses perjalanan dari satu daerah ke daerah lain yang kemudian diikuti gelombang migrasi berikutnya seiring dengan perkembangan kerajaan-kerajaan dan perdagangan (Tolla, 2010) serta pelayaran menuju daerah strategis dan kaya sumberdaya alam.

sejarah di situs-situs pesisir Kaimana?; (2) bagaimana karakter hunian awal sejarah yang tercermin dari tinggalan arkeologi yang ditemukan. Kedua masalah ini akan diteliti untuk memperoleh gambaran data dasar sebagai kajian awal peradaban di suatu kawasan yang dijaring Iwat studi pustaka, survei arkeologis, dan wawancara. Dengan demikian, kajian arkeologis pada kawasan situs masa sejarah Kaimana sebagai salah satu pusat peradaban pada masa lalu bertujuan untuk mengidentifikasi ragam artefak yang menggambarkan hunian awal sejarah di pesisir Kaimana, selanjutnya mengungkapkan karakter budaya hunian awal sejarah di pesisir Kaimana yang tercermin dari tinggalan arkeologi yang ditemukan.

\section{Kerangka Pemikiran}

Papua

memiliki

Gambar 1 : Peta Kabupaten Kaimana

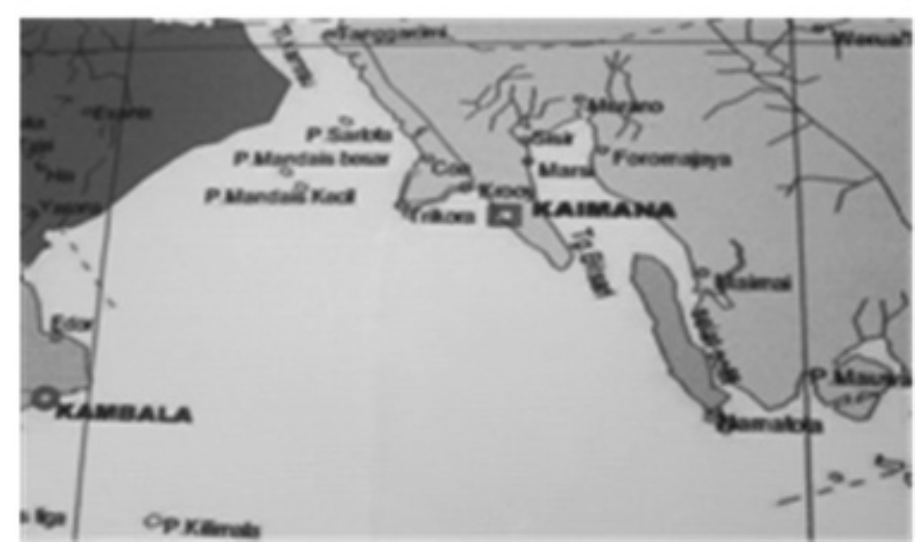

sumberdaya alam yang dibutuhkan kawasan lain di Nusantara, bahkan dunia; sebaliknya Papua juga menjadi pasar komoditas yang diproduksi atau dimiliki kawasan lainnya. Dalam jaringan perdagangan Nusantara, Papua dikenal sebagai penyedia komoditas pala, teripang, kayu masoi, burung indah, sisik penyu, rumput laut, sirip hiu, dan kerang mutiara. Komoditas

Diketahui bahwa letak geografis Kaimana sangat strategis, berada pada pesisir barat Papua. Dengan posisi strategis tersebut memungkinkan tumbuhnya jalur migrasi dan terjadinya kontak perdagangan antara barat dan timur Nusantara di kawasan tersebut. Oleh karena itu studi berkenaan dengan awal hunian masa sejarah di pesisir Kaimana sangat menarik dilakukan untuk mengungkapkan dua persoalan pokok, yaitu: (1) apa jejak hunian awal mutiara, terumbu karang dan kayu masoi yang disediakan orang Papua secara berkala diekspor ke Jawa untuk digunakan dalam pengobatan (Widjojo, 2013: 222).

Kedatangan para saudagar Nusantara ke Papua untuk berdagang, diduga kuat tidak lama berselang setelah terjadinya kontak perdagangan dengan Maluku. Kedatangan pedagang Nusantara semakin meningkat bersamaan dengan makin mapannya kekuasaan Tidore di Papua dengan 
mengirim utusan atau mengangkat pejabat lokal. Dalam survei yang dilakukan pada situs pemukiman di pantai baratdaya Papua, secara relatif dapat diduga bahwa hunian awal masa sejarah di pesisir Papua mulai dikendalikan oleh penguasa lokal atas perlindungan Kesultanan Tidore sekurang-kurangnya abad ke17 dan menjadi mapan pada abad ke-18 ditandai dengan terbentuknya petuanan di Raja Ampat, Fak-Fak dan Kaimana. Kaimana sendiri merupakan pelabuhan transit para pedagang yang dating melalui Seram yang terus berkembang dalam kontrol dinasti lokal menjadi Petuanan yang mendapat perlindungan Kerajaan Tidore (Mahmud, 2012: 32-33).

Meskipun dalam periode yang sama konsep kota dan permukiman abad pertengahan sangat umum dikembangkan di Nusantara, tetapi di pusat pemerintahan petuanan Kaimana belum ada gambaran nyata yang diketahui sampai sekarang. Konsep kota abad pertengahan di Nusantara pada umumnya, istana berada di pusat menghadap alun-alun yang berada di utara, sementara mesjid berada di barat (Mahmud, 2003: 29-46). Sementara di Papua, pemukiman pesisir yang dibangun pada area topografi tidak landai belum didokumentasikan secara memadai. Tentu ada keunikan yang berbeda dengan pemukiman dalam konsep Jawa dan beberapa kota lain di Sulawesi. Jika ada yang landai sangatlah sempit untuk membangun suatu pusat peradaban menurut konsep kota-kota abad pertengahan di Nusantara. Namun demikian, sejumlah aspek lainnya dalam lingkungan hunian yang dikembangkan secara adaptif dapat ditelusuri gambarannya dalam bidang: (i) arsitektur bangunan; (ii) industri kerajinan; (iii) komoditas impor; dan (iv) benda-benda warisan para elite (Mahmud, 2012: 39).

Seiring dengan meningkatnya perdagangan di kawasan timur, komunitas Cina juga bermigrasi ke wilayah timur Nusantara sekitar akhir abad ke-19 dan awal abad ke-20. Migrasi ini terjadi selain didorong faktor pergolakan politik di negeri Cina, juga karena alasan ekonomi. Migrasi selama periode ini meningkat ditunjang pula kebijakan dihapuskannya larangan migrasi bagi orang Cina oleh Kaisar Cina dalam tahun 1847 (Suryadinata, 1984). Tujuan migrasi orang Cina adalah daerah yang dilukiskan sebagai harapan hidup, serba indah dan nyaman yang dapat memberikan kehidupan baru (Idrus, 2004: 392). Pada awalnya orang Cina tinggal terpisah dalam lingkungannya masing-masing. Setelah pemerintah Belanda abad ke-20, orang-orang Cina diharuskan tinggal di bagian kota yang sudah ditentukan dan hanya boleh keluar dari daerah itu jika mendapat izin dari pemerintah Belanda. Kebijakan itu menyebabkan orang Cina tinggal berkelompok di kawasan yang disebut Kampung Cina (Chienesche Wijk) (Idrus, 2004: 397: Ongokham, 2008:3). Meskipun berada jauh dari negeri leluhur, kebiasaan migran Cina masih menerapkan budayanya yang berpengaruh pada karakter hunian mereka, seperti feng shui atau hong shui yang diterjemahan secara harafiah sebagai feng atau hong artinya angin, dan shui artinya air. Feng shui merupakan seni peletakan bangunan dan bermacam-macam struktur yang dibuat manusia untuk diselaraskan dengan alam (Lip, 1988:1). Feng shui mempunyai peranan yang penting dalam penentuan letak bangunan suci, makam serta bangunan lainnya bagi komunitas Cina. Hal tersebut berkaitan dengan kepercayaan tradisional mereka yang menganggap bahwa dengan menempatkan diri pada posisi yang baik menurut aturan Feng Shui ini, maka akan mendatangkan pengaruh baik, ketenangan, umur panjang, serta 
membawa berkah atau rezeki (Skinner, 1986:20).

\section{Jejak Arkeologis Hunian}

\section{(i) Tembikar}

Di sekitar monumen peninggalan arkeologi pada setiap situs hunian di pesisir Kaimana berserakan di muka tanah fragmen tembikar, jumlah terbanyak berada di situs Namatota, suatu teritori dinasti lokal yang cukup berpengaruh. Berbeda dengan situs Namatota, pada muka tanah situs Kampung Sran dan situs Kaki Air tidak banyak fragmen tembikar ditemukan yang disebabkan aktivitas urugan dan bangunan permanen yang sangat rapat satu dengan yang lain.

Dari sampel yang dikumpulkan secara acak di situs Namatota, pada umumnya fragmen tembikar diidentifikasi bekas tekan tatap pada permukaannya. Dilihat dari bahannya, --- berupa tanah liat dicampur sedikit pasir yang tidak ditemukan dalam formasi geologis Namatota ---, dapat diketahui bahwa tembikar tersebut berasal dari luar wilayah Kaimana. Fragmen tembikar yang ditemukan di situs Namatota semua berfungsi sebagai periuk yang dipasok dari industri yang masih menggunakan teknik tatap pelandas, sebagaimana dapat dilihat tabel di bawah. (ii) Keramik

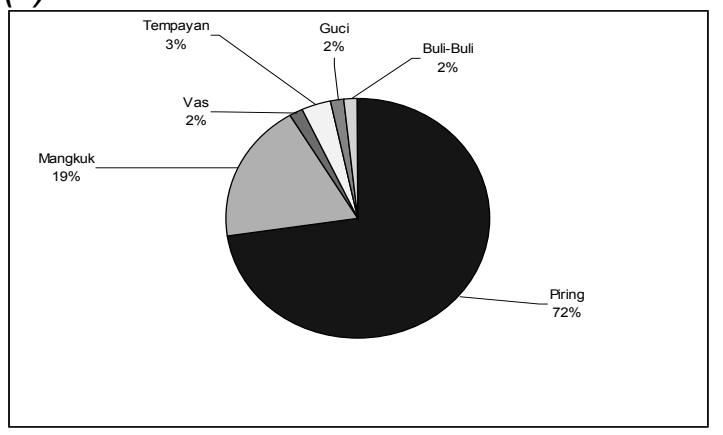

Gambar 2. Fungsi keramik berdasarkan sampel acak di situs-situs Kaimana (Sumber: penelitian tahun 2013)

Keramik merupakan salah satu barang mewah yang cukup diminati dan dipelihara di Kaimana sejak masa niaga abad ke-14 M. Meskipun orang Kaimana memiliki ketertarikan pada keramik kuno, tetapi tidak seperti di Sumatera, Jawa, dan Sulawesi, animo penggalian illegal cukup rendah. Suatu kondisi yang positif bagi upaya rekonstruksi sejarah-kebudayaan mereka.

Dalam survei yang dilakukan di tiga situs, ditemukan sejumlah keramik dalam skala waktu abad ke13- 20 Masehi. Berdasarkan sampel acak dapat diketahui bahwa $72 \%$ keramik berfungsi sebagai piring, $19 \%$ mangkuk, $3 \%$ tempayan, $2 \%$ guci dan $2 \%$ vas. (lihat chart, gambar 2 ). Temuan keramik dari situs hunian Kaimana

Tabel 1. Temuan Survei Fragmen Tembikar Situs Namatota

\begin{tabular}{|c|l|c|l|l|l|l|}
\hline No. & Bagian & Panjang & Lebar & Tebal & Warna & Fungsi \\
\hline 1 & Tepian & $3,5 \mathrm{~cm}$ & $3,5 \mathrm{~cm}$ & $0,7 \mathrm{~cm}$ & Merah core hitam & periuk \\
\hline 2 & Tepian & $3,5 \mathrm{~cm}$ & $3,7 \mathrm{~cm}$ & $0,8 \mathrm{~cm}$ & Coklat core coklat & periuk \\
\hline 3 & Tepian & $3,3 \mathrm{~cm}$ & $2,0 \mathrm{~cm}$ & $0,6 \mathrm{~cm}$ & Coklat core coklat & periuk \\
\hline 4 & Tepian & $2,5 \mathrm{~cm}$ & $2,7 \mathrm{~cm}$ & $0,5 \mathrm{~cm}$ & Coklat core coklat & periuk \\
\hline 5 & Tepian & $2,0 \mathrm{~cm}$ & $0,8 \mathrm{~cm}$ & $1,0 \mathrm{~cm}$ & Merah core merah & periuk \\
\hline 6 & Badan & $3,0 \mathrm{~cm}$ & $2,0 \mathrm{~cm}$ & $0,5 \mathrm{~cm}$ & Coklat core coklat & periuk \\
\hline 7 & Badan & $5,0 \mathrm{~cm}$ & $3,0 \mathrm{~cm}$ & $0,8 \mathrm{~cm}$ & Coklat core coklat & periuk \\
\hline 8 & Badan & $2,2 \mathrm{~cm}$ & $3,0 \mathrm{~cm}$ & $0,6 \mathrm{~cm}$ & Coklat core coklat & periuk \\
\hline 9 & Badan & $2,8 \mathrm{~cm}$ & $2,0 \mathrm{~cm}$ & $0,4 \mathrm{~cm}$ & Coklat core coklat & periuk \\
\hline 10 & Badan & $3,5 \mathrm{~cm}$ & $2,0 \mathrm{~cm}$ & $0,2 \mathrm{~cm}$ & Coklat core coklat & periuk \\
\hline 11 & Badan & $3,0 \mathrm{~cm}$ & $2,5 \mathrm{~cm}$ & $0,5 \mathrm{~cm}$ & Merah core merah & periuk \\
\hline 12 & Badan & $2,2 \mathrm{~cm}$ & $2,0 \mathrm{~cm}$ & $0,4 \mathrm{~cm}$ & Coklat core coklat & periuk \\
\hline 13 & Badan & $3,5 \mathrm{~cm}$ & $2,5 \mathrm{~cm}$ & $0,4 \mathrm{~cm}$ & Coklat core coklat & periuk \\
\hline 14 & Badan & $2,5 \mathrm{~cm}$ & $1,5 \mathrm{~cm}$ & $0,5 \mathrm{~cm}$ & Coklat core coklat & periuk \\
\hline 15 & Badan & $2,5 \mathrm{~cm}$ & $1,7 \mathrm{~cm}$ & $0,5 \mathrm{~cm}$ & Coklat core coklat & periuk \\
\hline 16 & Badan & $2,0 \mathrm{~cm}$ & $21 \mathrm{~cm}$ & $0,4 \mathrm{~cm}$ & Coklat core coklat & periuk \\
\hline 17 & Badan & $1,5 \mathrm{~cm}$ & $1,0 \mathrm{~cm}$ & $0,4 \mathrm{~cm}$ & Coklat core coklat & periuk \\
\hline
\end{tabular}

Sumber: Data penelitian arkeologi di Kaimana, Papua Barat, tahun 2013 
memperlihatkan bahwa pada dasarnya barang-barang tersebut dibeli untuk keperluan sehari-hari rumah tangga. Hanya beberapa keramik eksklusif untuk hiasan (vas) bagi kalangan elite dan piring digunakan dalam ritual tradisi ziarah pada penguburan orang yang dihormati, khususnya raja (lihat Tabel 2, 3 dan 4).

Tabel 2. Temuan Survei Keramik Situs Kampung Sran

\begin{tabular}{|c|c|c|c|c|}
\hline No & Bagian Fragmen & Bentuk & Jenis Fragmen & Jumlah \\
\hline 1 & Tepian & Piring & Eropa abad ke-20 M & 6 \\
\hline 2 & Badan & Piring & Ching abad ke-17-18 M & 3 \\
\hline 3 & Badan & Mangkuk & Ching abad ke-17-18 M & 2 \\
\hline
\end{tabular}

Sumber: Data penelitian arkeologi di Kaimana, Papua Barat, tahun 2013 dan 2014

Tabel 3. Temuan Survei Keramik Situs Kaki Air

\begin{tabular}{|c|l|l|l|c|}
\hline No & Bagian Fragmen & Bentuk & \multicolumn{1}{c|}{ Jenis Fragmen } & Jumlah \\
\hline 1 & Badan & Piring & Ming abad ke-15-16 M & 1 \\
\hline 2 & Badan & Piring & Ching abad ke-17-18 M & 2 \\
\hline 3 & Dasar & Piring & Eropa abad ke-20 M & 1 \\
\hline 4 & Badan & Piring & Eropa abad ke-20 M & 1 \\
\hline
\end{tabular}

Sumber: Data penelitian arkeologi di Kaimana tahun 2013

Tabel 4. Temuan Survei Fragmen Keramik/Stonewere Situs Namatota

\begin{tabular}{|c|l|l|l|c|}
\hline No & Bagian Fragmen & \multicolumn{1}{|c|}{ Bentuk } & \multicolumn{1}{c|}{ Sumber Kiln } & Jumlah \\
\hline 1 & Badan & Mangkuk & Sung abad ke-13 M & 2 \\
\hline 2 & Tepian & Piring & Yuan abad ke-14 M & 1 \\
\hline 3 & Badan & Vas & Yuan abad ke-14 M & 1 \\
\hline 4 & Badan & Mangkuk & Yuan abad ke-14 M & 2 \\
\hline 5 & Badan & Buli-buli & Yuan abad ke-14 M & 1 \\
\hline 6 & Badan & Piring & Yuan abad ke-14 M & 1 \\
\hline 7 & Badan & Piring & Sukhothai 13-14 M & 1 \\
\hline 8 & Badan & Tempayan & Vietnam abad ke-15 M & 1 \\
\hline 9 & Badan & Piring & Vietnam abad ke-15 M & 1 \\
\hline 10 & Tepian & Mangkuk & Ming abad ke-15-16 M & 1 \\
\hline 11 & Tepian & Piring & Ming abad ke-16-17 M & 4 \\
\hline 12 & Badan & Mangkuk & Ming Swatow abad ke-16 M & 2 \\
\hline 13 & Dasar & Mangkuk & Ming Swatow abad ke-16 M & 1 \\
\hline 14 & Badan & Tempayan & Ming Swatow abad ke-16 M & 1 \\
\hline 15 & Badan & Piring & Ming abad ke-16-17 M & 3 \\
\hline 16 & Tepian & Mangkuk & Ming abad ke-16-17 M & 1 \\
\hline 17 & Tepian & Piring & Ching abad ke-17-18 M & 2 \\
\hline 18 & Tepian & Piring & Ching abad ke-18-19 M & 4 \\
\hline 19 & Badan & Piring & Ching abad ke-18-19 M & 1 \\
\hline 20 & Dasar & Piring & Ching abad ke-19-20 M & 1 \\
\hline 21 & Tepian & Piring & Eropa abad ke-19-20 M & 5 \\
\hline 22 & Badan & Piring & Eropa abad ke-19-20 M & 2 \\
\hline 23 & Dasar & Piring & Eropa abad ke-19-20 M & 1 \\
\hline 24 & Badan & Guci & Eropa abad ke-19-20 M & 1 \\
\hline
\end{tabular}

Sumber: Data penelitian arkeologi di Kaimana, Papua Barat tahun 2013 dan 2014 
(iii) Makam dan Nisan

Makam megah bagi para raja dan ulama menjadi fenomena umum di Nusantara, terutama sejak ke-16-19 M. Pada situs Sran (kota Kaimana) diketahui adanya makam muslim dan komunitas Cina di tiga lokasi. Makam raja dan keluarganya terletak di sisi utara masjid, sedangkan makam ulama terletak di sisi tenggara masjid di dalam pemakaman umum. Kompleks makam di sisi utara masjid dianggap suci karena pada situs ini beberapa raja Sran dikebumikan, diantaranya Iwafusa (Raja Sran V) yang berkuasa dari 1898--1923; istri Raja Sran VI (Salma Hakim); dan Achmad Aituarauw (Raja Sran VI) yang berkuasa dari 1923-1966. Pada kompleks makam raja dan ulama diidentifikasi tiga tipe nisan, yaitu: (1) tipe mahkota teratai, (2) tipe kubah masjid; (3) tipe massif.

Makam komunitas Cina terletak di sisi timur masjid Kampung Sran atau sebelah tenggara pecinan. Di situs makam Cina pada dasarnya memiliki tipe yang hampir sama. Makam di kompleks kuburan Cina ini berhiaskan motif naga dan flora, dengan tulisan huruf Cina warna kuning keemasan. Nisan Cina disebut dengan bongpai. Bongpai orang kaya dihiasi ornamen yang beragam, sedangkan bongpai orang miskin lebih sederhana, dan polos (Lan, 2013:216).

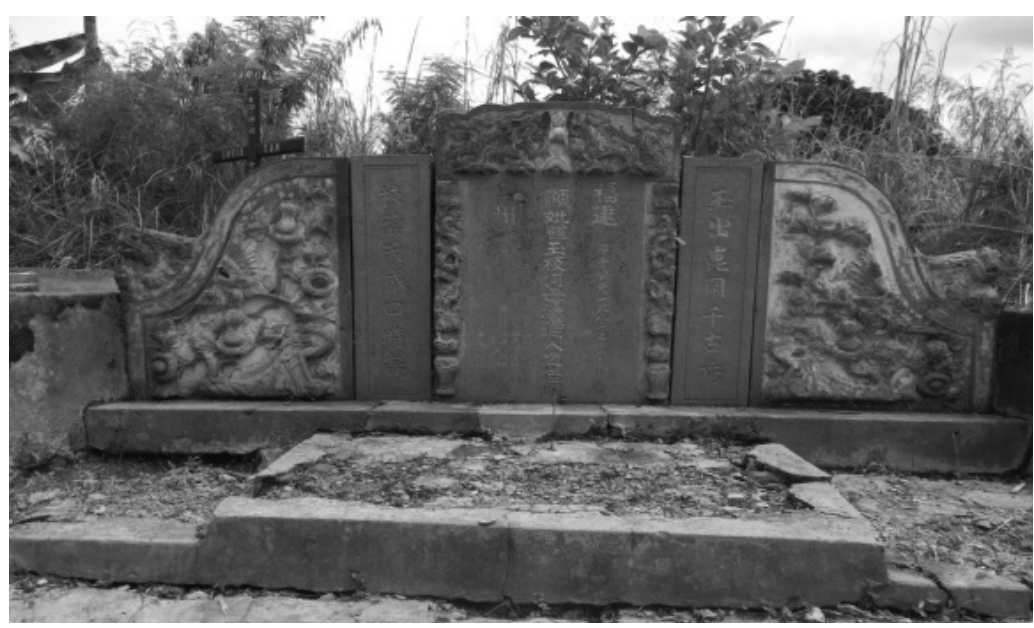

Gambar 3. Makam Tionghoa arah hadap barat (dokumentasi Balai Arkeologi Jayapura)
Kompleks kuburan Tionghoa berada pada punggung dan lereng bukit yang memanjang dari baratlaut ke timurlaut, kira-kira 200 meter ke arah tenggara kompleks pertokoan Pecinan. Lokasi makam di bukit ini berdasarkan feng shui dianggap memiliki arus ch'i yang baik bagi komunitas Tionghoa di Kaimana. Di dalam kompleks makam Tionghoa terdapat 22 buah yang orientasinya mengikuti bidang topografi bukit. Makam yang berada di lereng sisi utara, sebanyak 7 buah menghadap ke utara dan 1 buah menghadap ke badardaya. Makam Tionghoa yang berada di puncak bukit terdapat 2 buah menghadap ke utara dan 2 buah menghadap ke baratdaya. Sementara itu, makam yang berada di lereng sebelah selatan sebanyak 8 buah menghadap ke selatan dan 2 buah menghadap ke barat.

Makam di kompleks kuburan Tionghoa ini berhiaskan motif naga dan flora, dengan tulisan huruf Cina warna kuning keemasan. Nisan Tionghoa disebut dengan bongpai. Bongpai orang kaya dihiasi ornamen yang beragam, sedangkan bongpai orang miskin lebih sederhana, dan polos (Lan, 2013:216). Makam Tionghoa dibuat menurut kepercayaan Hong Sui yang berarti Angin dan Air. Kepercayaan Hong Sui menetapkan antara lain, tempat dan letaknya makam. Tempat ini dipilih oleh seorang sinshe Hong Sui, yang diminta pertolongannya oleh keluarga yang bersangkutan. Sinshe ini lalu mencarikan suatu tempat yang baik. Setahun sekali, pada hari Tjeng Beng, orangorang akan berziarah ke makam leluhurnya dan membersihkannya dengan membabat rumput dan alang-alang yang memenuhi makam. 


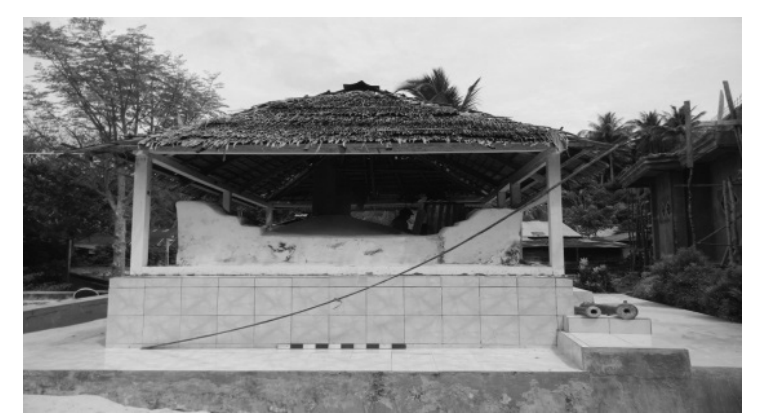

Gambar 4. Makam raja di Namatota (dokumentasi Balai Arkeologi Jayapura)

Di situs Namatota diidentifikasi satu kompleks makam kuno yang terintegrasi dengan masjid. Pada kompleks makam yang berada di sebelah barat masjid Namatota diidentifikasi tiga tipe makam, yaitu: (1) makam bercungkup; (2) makam susunan batu alamiah, tanpa nisan; (3) makam dengan jirat dan nisan. Nisan pada situs ini dibedakan atas tiga jenis, yaitu: (1) nisan silindrik dari bahan kayu dan batu; (2) nisan mahkota teratai, bahan kayu; (3) nisan massif, bahan kayu. Makam raja ini memiliki pintu tepat di tengah dinding timur. Di kedua sisi pintu diletakkan masing-masing dua meriam (lela) yang moncong menghadap ke utara, sedangkan dua lainnya menghadap ke selatan.

\section{(iv) Masjid}

Di pesisir Kaimana memiliki dua situs yang memiliki bekas lokasi masjid tua. Meskipun kedua masjid telah mengalami renovasi berkali-kali, namun sejarah dan dokumentasinya masih dapat diperoleh dari informan, Maryam Achmad Aituarauw. Kedua situs yang dapat diidentifikasi lokasi bekas masjid tuanya terdapat di situs Kampung Sran dan situs Namatota. Konteks yang menegaskan sebagai masjid tua dapat diketahui dari kehadiran makam-makam raja dan keluarga muslim di sekitarnya.

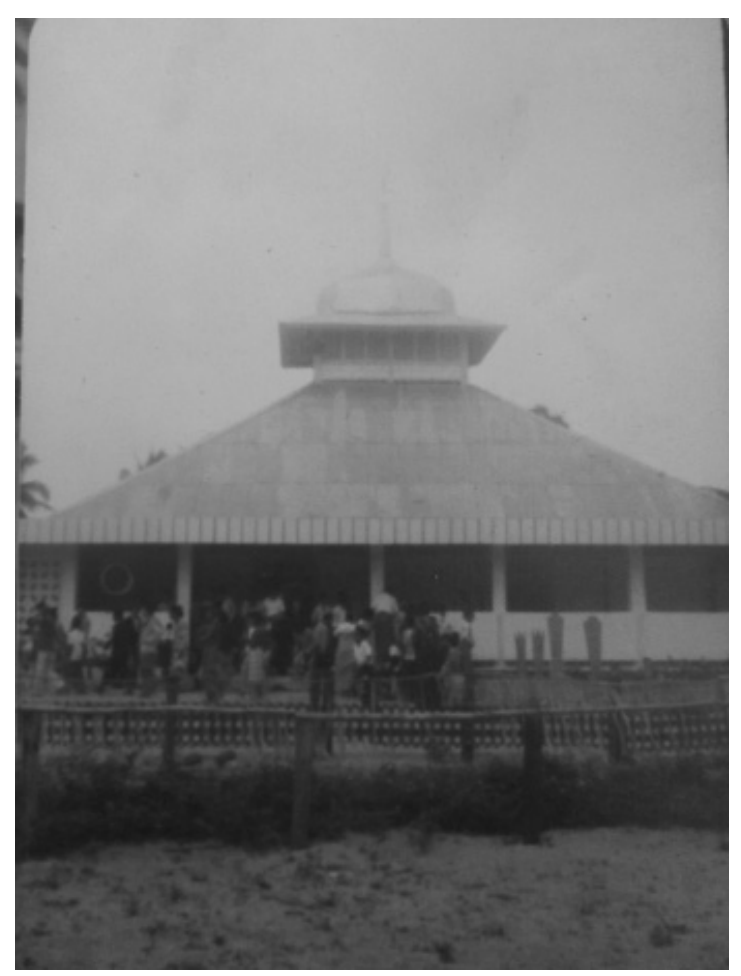

Gambar 5. Masjid Renovasi ke tiga tahun 1970 (Sumber: Maryam Achmad Aituarauw)

Masjid tua di kampung Sran, Kota Kaimana berbentuk persegi empat tanpa teras dengan satu pintu di sisi Timur, berukuran $15 \times 15$ meter. Mulanya bangunan masjid dari konstruksi kayu dengan dinding dari pelepah sagu dan atap rumbia (daun sagu). Masjid tertua awalnya tanpa jendela, hanya bagian atas diberi rongga besar sebagai lubang angin. Konstruksi atap berbentuk tumpang sebagaimana kebanyakan masjid kuno di Nusantara. Pemugaran yang dilakukan pada tahun 1953 bentuk masjid tetap dipertahankan, namun dinding dibuat setengah permanen; bagian bawah sudah menggunakan konstruksi batu dan semen dengan setengah dindingnya. Bagian dinding sebelah atas menggunakan papan dan balok.

Renovasi selanjutnya pada tahun 1970, masjid di situs Sran dikembangkan dengan menambah serambi pada sisi timur, selatan dan utara. Penambahan ini nampak terkait dengan meningkatnya fungsi 
sosial masjid, bukan sekedar untuk ibadah keagamaan, tetapi juga untuk pendidikan, khususnya pengajaran agama Islam.

Hampir sama dengan perkembangan masjid tua di situs Sran, masjid tua di kampung Namatota juga mengalami beberapa kali renovasi, meskipun ukuran dan bentuk masih banyak yang dipertahankan. Masjid tua dikampung Sran juga dahulu dari bahan alamiah yang disediakan lingkungan, sekarang dengan perkembangan fungsi sosial dan kemampuan ekonomi penduduknya, masjid telah berubah baik bahan maupun bentuk. Dahulu masjid di kampung Namatota tidak memiliki kubah, sekarang memiliki kubah. Hal yang penting diketahui dari kedudukan masjid dikedua situs adalah, masjid senantiasa berada tidak jauh dari istana raja. Hal ini menunjukkan suatu konsep hubungan erat antara agama dan kekuasaan dalam mengatur masyarakatnya di masa lalu. Meskipun demikian, raja-raja muslim nampaknya juga mengembangkan sikap toleran terhadap komunitas non-muslim dengan memberi tempat mengembangkan pemukiman, penguburan, dan rumah ibadah. Di lingkungan situs Sran terdapat gereja, pemukiman Cina, kuburan Cina. Hal ini menggambarkan sudah terbentuknya sikap budaya multikulturalisme yang juga tetap terpelihara sampai sekarang oleh masyarakat Kaimana.

\section{(v) Sumur dan Sumber Air}

Fasilitas sumur tidak dapat dipisahkan dengan kebutuhan penduduk yang bermukim. Air merupakan kebutuhan hidup seharihari yang harus terpenuhi dalam membangun suatu pemukiman. Penempatan sumur ditengah pemukiman situs Namatota selain menggambarkan pertimbangan akses bagi semua penduduk situs Namatota, juga mempertimbangkan kualitas air pada pulau tersebut. Penempatan sumur nampak juga terkait dengan kemudahan pemenuhan sumber air yang terkait dengan masjid. Sumur terletak 30 meter di sebelah utara masjid Namatota. Dalam survei ditemukan 1 buah sumur tua di situs Namatota, terletak tepat di pusat ruang pemukiman, di sebelah timur masjid atau di utara rumah raja. Sekarang sumur ini sudah direnovasi menggunakan dinding tembok berlapis plaster semen, berdenah persegi empat. Dinding sumur terbuat dari bahan batu karang dengan spesi pasir dan semen, berukuran panjang 2,3 meter, lebar 1,98 meter, tinggi dinding 0,35 meter, dan ketebalan dinding 24 $\mathrm{cm}$.

Berbeda dengan di Namatota, di kawasan Tanjung Bicari, ---khususnya di situs Sran dan Kaki Air kawasan kota Kaimana---, sumber air untuk kebutuhan sehari-hari tergantung pada Sungai Tanggorami, Sungai Tarobe, dan mata air Jalan Sisir. Pembuatan sumur baru dilakukan pada awal abad ke-20 seiring dengan makin padatnya jumlah penduduk serta upaya pembangunan yang dilakukan pemerintah Belanda.

\section{(vi) Bangunan Pecinan}

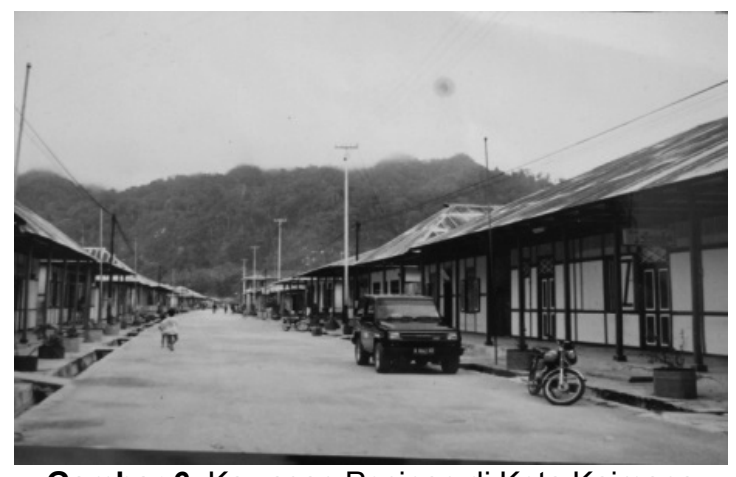

Gambar 6. Kawasan Pecinan di Kota Kaimana (dokumentasi Balai Arkeologi Jayapura)

Komunitas Cina di pesisir Kaimana bermukin berkelompok di pusat pedagangan. Bangunan pecinan terkonsentrasi di Jalan Trikora yang melintang utara-selatan, tepat di pesisir 
pantai barat. Perkampungan Cina tampak merupakan deretan rumahrumah yang berhadap-hadapan di sepanjang Jalan Trikora. Pertokoan Pecinan berjajar di kedua sisi Jalan Trikora berorientasi utara-selatan. Sembilan belas rumah menghadap ke timur, dan lima belas rumah menghadap ke barat. Deretan rumah tersebut terdiri dari rumah petak di bawah satu atap yang semuanya tidak mempunyai pekarangan. Sebagai ganti pekarangan di tengah rumah terdapat ruangan tanpa atap untuk menanam tanaman, mencuci piring dan menjemur pakaian. Bagian paling depan dari rumah difungsikan sebagai ruangan tamu dan tempat meja abu. Biasanya ruangan depan juga dipakai sebagai toko, sehingga meja abu harus ditempatkaan di ruangan belakang. Selanjutnya, di dalam rumah untuk menuju ke dapur dan kamar mandi bagian belakang melalui lorong yang di sebelah kirikanannya terdapat kamar tidur.

Konstruksi rumah komunitas Tionghoa di Kaimana menggunakan atap seng dan tiang balok kayu. Model atap yang melengkung pada keempat ujungnya dengan ukir-ukiran berbentuk naga sudah tidak ditemukan lagi. Konstruksi dinding dibuat dari tembok yang diperkuat dengan rangka bambu.

Berdasarkan data survei, diketahui bahwa bangunan di dalam kantong pemukiman komunitas Cina di Kaimana memiliki lima tipe, yaitu:

a. Tipe bangunan berpintu samping, dengan teras bertiang. Bangunan ini memiliki dua pintu samping pada sisi utara dan selatan bangunan serta dua pintu utama dan tiga jendela depan. Bangunan berfungsi sebagai rumah-toko.

b. Tipe bangunan tanpa pintu samping dengan dua pintu utama dan tiga jendela depan dengan teras bertiang, berfungsi sebagai rumahtoko. c. Tipe bangunan tanpa pintu samping dengan teras tanpa tiang. Bangunan tipe ini sama dengan tipe (b), memiliki dua pintu utama dan tiga jendela depan, juga berfungsi sebagai rumah-toko.

d. Tipe Aula. Bangunan ini memiliki satu pintu besar dan empat jendela di depan dengan ruangan yang tanpa sekat. Bangunan ini khusus digunakan untuk hiburan, yaitu billiards (bola sodok).

e. Tipe gudang. Bangunan ini hanya memiliki satu pintu besar dan tinggi tanpa jendela.

\section{Keragaman Budaya Pesisir dan Pulau}

Daerah Kaimana berada di wilayah yang strategis menjadi feederport yang menunjang kegiatan perdagangan. Feederport ialah pusat pengumpulan dan distribusi komoditas dagang yang berfungsi mengumpul hasil bumi setempat untuk dibawa ke pelabuhan utama (enterport) tempat kegiatan perdagangan antarbangsa berlangsung (Khaw, et.al., 1984: 53). Peran Kaimana sebagai feederport dimungkinkan oleh letaknya di sebuah tanjung yang berhadapan langsung dengan beberapa pelabuhan utama (enterport), Banda dan Bacan.

Hubungan pelayaran dan perdagangan antara Kaimana dengan wilayah Nusantara secara intensif melahirkan ragam budaya setempat, baik akibat akulturasi maupun assimilasi. Budaya pesisir yang beragam bisa dilihat dari bentuk dan tipe-tipe kuburan, jenis medium/sarana ibadah (medium ritual lokal masjid, gereja, dan ritual Cina) serta berbagai jenis sisa barang dagangan, seperti tembikar dan keramik. Akibat sentuhan kebudayaan luar, masyarakat pesisir Kaimana yang pada awalnya hanya hidup dalam tatanan budaya lokal, secara berlahan-lahan menyerap unsur peradaban Islam, lalu Kristen dan 
Eropa, dan juga secara terbatas hidup berdampingan dengan komunitas Cina.

yang monumental tampak dari keberadaan masjid, makam ulama dan raja-raja muslim, konsep orientasi, serta penggunaan huruf Arab. Pada lingkungan ruang yang sama kita dapat juga menemukan kehadiran pengaruh peradaban Eropa yang tampak dari keberadaan gereja, konsep kota, bangunan militer, rumah pejabat, dan persenjataan modern. Kehadiran peradaban Cina yang baru mulai berkembang sejak awal abad ke20, tampak menyisip diantara anasir lokal, Islam dan Eropa membentuk kantong pemukiman ekslusif pecinan dengan konsep rumah-toko (ruko) dan kompleks pemakaman. Sementara itu, budaya lokal tetap bertahan dan diwariskan oleh penduduk setempat di wilayah pedalaman berupa: penguburan pada ceruk dan gua yang disertai bekal kubur, hidup berburu dan meramu yang hasilnya biasa dibarter dengan penduduk yang bermukim di daerah pesisir pantai, ritual animisme, alat tulang dan batu, pemukiman yang menyebar, dan lain sebagainya. Tidak jarang terjadi silang budaya antara penduduk lokal dan pendatang sepanjang masa sejarah yang kemudian menjadi karakter budaya hunian masa awal sejarah.

\section{Karakter Budaya Hunian Awal Sejarah}

Karakter budaya maritim yang inklusif dan adaptif di Kaimana dipengaruhi pelayaran, perdagangan, serta jejaring kekerabatan.. Lingkungan budaya maritim tampak dari pentingnya pelabuhan alam di setiap situs hunian yang ditemukan. Semua situs-situs masa sejarah selalu ditemukan di pesisir dan jalur hubungan antar situs pada umumnya hanya dapat ditempuh dengan perahu dan jalur air. Bandar alam yang sekarang terus berkembang menjadi pelabuhan penumpang dan barang ditemukan di lingkungan situs Sran dan Namatota. Perkembangan pelabuhan maritim di kedua situs kemudian memberi legitimasi kekuasaan dua dinasti di wilayah Kaimana; Raja Namatota dengan wilayah Namatota dan Raja Sran disebut juga Raja Komisi, dengan wilayah meliputi Sran dan Adi Jaya. Kedua istana merupakan kerabat dekat dan sampai sekarang masih menjaga jaringan sosial-ekonomi dan kekerabatannya.

Sumber tradisi tutur menyebutkan, pada awalnya pusat kekuasaan Kerajaan Sran berada di Adi Jaya, dimana dalam perkembangannya kemudian pindah ke Kampung Sran, suatu kampong yang berada diujung tanjung. Situs Sran berdasarkan pertanggalan C.14 (arang) hasil ekskavasi Balai Arkeologi Jayapura tahun 2014 berusia 1670 $\pm 160 \mathrm{BP}$ atau dihuni mulai sekitar akhir abad ke-3 atau awal abad ke-4 Masehi, jauh sebelum kontak dagang dengan Maluku terjadi. Dalam periode tersebut diduga situs Sran masih dihuni oleh etnis lokal dengan budaya asli. Kehadiran para pedagang seiring dengan meningkatnya pelayaran niaga abad pertengahan (abad ke-14 hingga 17 Masehi) dan disusul pemindahan pusat kekuasaan Adi Jaya membangun kontak budaya dan menambah unsur baru yang dibawa oleh para pedagang dan migran.

Pada tahun 1922 Raja Achmad Aituarauw yang kemudian menjadi Raja Sran VI, menata ibu kota Kaimana, membuka jalan-jalan, dan menerima pedagang-pedagang Seram, Ternate, Tidore, Bugis-Makassar, Cina, dan Arab. Sikap ini menunjukkan karakter inklusif penguasa dan penduduk kedua situs. Sikap inklusif terhadap pengaruh luar mengenalkan satu sisi pola 
ekonomi baru (dagang) yang secara arkeologis dapat dibuktikan dengan penemuan sejumlah artefak, seperti fragmen keramik, tembikar, dan sisasisa peralatan besi. Komoditas dagang tersebut dibawa dan ditukarkan dengan komoditas lokal yang dicari oleh pedagang asing, diantaranya berasal dari Maluku, Jawa, Arab , Eropa, dan Cina.

Pedagang Arab mendapat jalan ke Papua, lewat jalur Kesultanan Tidore dan Bacan (Prasetyo, 2011: 76). Mereka mendapat sambutan atau bahkan kalangan ulama diundang penguasa lokal guna mengajarkan dan menjaga fungsi hukum Islam yang dengan itu akan meningkatkan reputasi istana. Bisa jadi ketika tekanan Portugis dan VOC yang semakin kuat di Maluku, mereka mencoba mengeksplorasi wilayah Kepala Burung Papua untuk mempertahankan eksistensinya dalam perdagangan. Kelihatannya, saudagar Arab mudah diterima masyarakat lokal karena meskipun mereka taat menjalankan agama, tetapi tidak menyebarkan agamanya dengan cara paksa atau fanatik (Berg, 2010: xiv). Selain pedagang Arab dan Tidore, juga dikenal pedagang Bugis yang datang membawa gong, gelang Bugis dan anting-anting. Pada awal peradaban ini juga sudah dikenal pandai besi yang diperkenalkan orang Kei dan sekarang masih ada satu meneruskan keterampilan tersebut.

Sifat inklusif tampak pula dari penerimaan anasir baru dari peradaban luar dalam lingkungan hunian di pesisir Kaimana. Penemuan vas keramik sebanyak $2 \%$ (Lihat chart, gambar 2) sebagai hiasan menunjukkan telah muncul perhatian pada aspek estetika. Secara sosial, mereka juga mulai mengenal cara penyimpanan air dengan tempayan serta adab makan dengan piring (lihat chart, gambar 2 dan tabel 2, 3, 4). Dengan penemuan mangkuk keramik
Yuan dan Ming dalam persentasi besar $(19 \%)$ kemungkinan penduduk pesisir Kaimana sejak abad ke-14 - $15 \mathrm{M}$ juga sudah mengenal makanan berkuah dari bangsa luar, terutama kalangan elite. Demikian pula aspek religi, sejak masuknya pedagang Maluku, Arab, Bugis, Eropa dan Cina, penduduk lokal yang memiliki kepercayaan lokal mulai mengenal cara penguburan dengan bentuk makam dan nisan khas. Dari inskripsi nisan diketahui bahwa budaya hunian di pesisir Kaimana mendapat pengaruh agama Islam. Mereka juga mulai mengenal pejabat qadi terutama di pusat-pusat kerajaan. Peran qadi di Kaimana masa lalu sama dengan di Hadramaut, daerah yang banyak mempengaruhi ajaran muslim di Indonesia. Di Hadramaut, para qadi memiliki kekuasaan peradilan perdata dan pidana pada perkara perkawinan dan perkara lain yang berkaitan dengan hukum keluarga berdasarkan kitab hukum mazhab Syafi'i (Berg, 2010: 43).

Karakter budaya hunian menunjukkan keterbukaan dan toleransi yang cukup tinggi. Di wilayah pesisir Kaimana antara kantong pemukiman muslim, non-muslim dan pecinan terintegrasi. Pemukiman muslim ditandai dengan makam dan masjid yang berada di bibir tanjung; kaum kristiani kebanyakan menghuni dataran dan perbukitan dengan gereja di punggung suatu bukit berhadapan langsung dengan hunian muslim dan komunitas Cina di pusat perekonomian dalam jarak yang dapat dijangkau dengan mudah. Unsurunsur pemukiman dikembangkan secara adaptif dengan lingkungan yang nampak dari materi-materi budaya yang ditemukan. Misalnya, nisan-nisan muslim yang terbuat dari bahan kayu yang berasal di sekitar lingkungan hunian. Komunitas Cina menerapkan konsep kosmologinya dengan menyesuaikan pada kondisi 
lingkungan geomorfologis setempat.

Komunitas Cina di Kaimana bermukim dalam satu pemukiman yang diberi nama Pecinan. Keberadaan komunitas Cina di Kaimana merupakan generasi ke empat (wawancara Maryam Achmad Aituarauw, Desember 2013). Sayang sekali belum diperoleh jejak migran Cina generasi pertama dalam penelitian ini. Keturunan Cina di pesisir Kaimana terdiri dari marga Tan, Lie, Kwan, Ham, Tjeng Sun An, The Tek, dan Ui. Diketahui bahwa margamarga tersebut merupakan bagian dari komunitas suku Hokkian dan Kanton yang termasuk dalam suku Han yang berdiam di Propinsi Fujian dan Guangdong, Cina Selatan (Tan, 2008: 4).

Komunitas Cina yang datang ke Kaimana membawa unsur budaya leluhurnya. Mereka mengembangkan pemukiman Pecinan dengan ciri rumah tinggal, sekaligus berfungsi sebagai toko yang dibangun berhadapan satu dengan lainnya, hanya dipisahkan oleh jalan di tengahnya. Jalan yang memisahkan blok rumah di Pecinan berorientasi utara-selatan, sementara rumah menghadap timur dan barat. Orientasi rumah komunitas Cina ini terkait dengan feng-shui. Tiap arah dalam feng-shui memiliki pengertian baik atau buruk. Arah utara dihindari karena mereka meyakini orientasi tersebut penuh dengan kegelapan; sementara arah timur digambarkan sebagai posisi yang dinamis dan penuh kedamaian (Dian, 1996:29-31). Dengan pola hunian yang dibentuk, komunitas Cina secara arkeologis telah memberi kontribusi pada perkembangan karakter pluralisme hunian pesisir pantai Kaimana.

Selain pluralisme, budaya maritim juga merupakan karakter dasar setiap hunian masa awal sejarah di pesisir Kaimana. Letak situs hunian di pantai, dengan pelabuhan alam serta sisa makanan yang dominan berasal dari laut merupakan indikator kuat telah berkembangnya budaya maritim. Budaya maritim yang terintegrasi dengan perdagangan antar pulau di wilayah pesisir Kaimana, juga memberi ruang hunian yang toleran terhadap migran yang berasal dari luar sebagaimana dibuktikan keberadaan makam keturunan Maluku, Arab, dan Cina. Interaksi perdagangan antara masyarakat Kaimana dengan para pedagang luar telah berlangsung lama, dan kemungkinan semakin meningkat sejak abad ke-15 Masehi (Mahmud, 2012: 31-32). Melalui perantaraan pedagang, berbagai jenis barang impor diperoleh masyarakat Kaimana dari bangsa lain termasuk Eropa, seperti tembikar, keramik, peralatan besi, dan persenjataan. Persenjataan lela (meriam Portugis) misalnya, mempunyai pengaruh besar terhadap budaya pesisir Kaimana. Lela yang dahulu merupakan peralatan perang, kemudian oleh suku Kowiai menjadi harta istimewa yang berfungsi sebagai mas kawin, dimana menjadi hak, kewajiban dan kedudukan laki-laki (calon suami) dan anak-anaknya. Selain anasir Portugis, masyarakat Kaimana juga kemudian berdampingan dengan komunitas budaya Cina.

Pada masa kolonial, komunitas Cina menjadi mitra dagang Belanda khususnya di bidang distribusi barang antara masyarakat pribumi dan penguasa kolonial. Ketersediaan sumberdaya alam Kaimana dan posisi strategisnya dalam transmaritim merupakan daya tarik bagi pihak Belanda menjadikan salah satu pusat militer pertama di Papua. Dengan kehadiran pihak Belanda, anasir Eropa masuk di dalam lingkungan situs hunian Kaimana, berupa gereja, pola pemukiman, rumah pejabat, tangsi militer, sekolah dan perkantoran. Kehadiran anasir Eropa yang berkembang bersama dengan unsur budaya lokal, Islam dan 
Cina memberi kita sekarang suatu bukti multikulturalisme yang menjadi kearifan dan terus dipelihara penduduk Kaimana sampai saat ini.

\section{PENUTUPAN}

Ragam tinggalan arkeologis yang ditemukan dalam penelitian situs masa awal sejarah di pesisir Kaimana, meliputi peninggalan monumental dan relics (artefak bergerak). Jejak peninggalan monumental di situs Kampung Sran yang diidentifikasi berupa bekas lokasi masjid, kompleks makam raja dengan nisannya, serta kompleks makam Cina. Di kawasan situs Kelurahan Kaimana dapat diidentifikasi monumen arkeologis berupa bangunan kompleks pertokoan yang sekaligus menjadi perkampungan Cina dan situs kaki air. Sementara di situs Kampung Namatota ditemukan sumur tua, lokasi masjid, makam raja, dan pusat kampung. Dalam penelitian juga ditemuan artefak yang bersifat relics, meliputi fragmen keramik dan tembikar yang ditemukan di ketiga lokasi situs yang disurvei. Selain itu, anasir etnoarkeologis juga direkam, berupa tempat siri pinang yang menjadi warisan kerabat raja Kaimana dan wadah keramik untuk ritual ziarah pada makam raja di situs Namatota.

Berdasarkan pertanggalan C.14, situs Sran dihuni sejak akhir abad ke-3 dan awal abad ke-4 Masehi oleh pribumi yang mengembangkan budaya asli. Tetapi hubungan dengan dunia luar akibat perdagangan berdasarkan indikasi artefak keramik Sung diduga baru dimulai abad ke-13
M dengan memanfaatkan pulau-pulau di depan daratan pulau besar Papua, seperti situs Pulau Adi dan Kampung Namatota. Kontak dagang yang terus berkembang meningggalkan jejak budaya yang beragam pada situs pesisir dan pulau-pulau sekitar.

Dengan keragaman artefak yang ditemukan dapat diketahui bahwa dalam masa awal sejarah di situs Kaimana telah berkembang budaya yang multikultur. Penduduk yang menghuni situs ini mengembangkan kebudayaan lokal dan berasimilasi dengan unsur budaya luar yang masuk, baik dari Maluku, pedagang Arab dan Melayu, maupun Cina dan Eropa. Dalam keragaman budaya tersebut, komunitas Kaimana dikendalikan secara teokratis dari keluarga kerajaan dan memiliki hirarki yang tegas sebagaimana tampak pada makanmakam kuno yang ditemukan berada dalam kelompok yang serumpun sesuai dengan strata sosialnya. Terdapat pemisahan makam keluarga raja, makam ulama, makam rakyat biasa, dan makam Cina. Meskipun memiliki beragam budaya, aktivitas masyarakat di situs hunian patut diduga memiliki hubungan secara sosial-ekonomi di Pecinan dan pelabuhan atau pesisir pantai. Dari infrastruktur, letak geografisnya dan sisa makanan dari laut yang ditemukan, situs hunian masa awal sejarah Kaimana mencerminkan karakter peradaban maritim yang terbuka, maju, dan adaptif dengan anasir dari luar melingkupi segala aspek kehidupan: sosial, ekonomi, budaya, sejarah, hingga religi. 


\section{DAFTAR PUSTAKA}

Alatas, Ismail Fajrie. 2010. "Menjadi Arab: Komunitas Hadramî, Ilmu Pengetahuan Kolonial dan Etnisitas", dalam L.W.C. van den Berg, Orang Arab Nusantara, Cet. 1. Jakarta: Komunitas Bambu.

Berg, L.W.C van den. 2010. Orang Arab di Nusantara. Cet. 1. Jakarta: Komunitas Bambu.

Dian, Rtn. 1996. Logika Feng Shui: Seni Mencapai Hidup Harmonis dan Bahagia dalam Keberuntungan Bumi Jilid 1. Jakarta: Elex Media Komputindo.

Idrus, Rinawati. 2004. "Budaya Etnis Tionghoa di Makassar (Studi Kasus Ornamensi pada Klenteng Ibu Agung Bahri)" dalam Iwan Sumantri (ed.). Kepingan Mozaik Sejarah Budaya Sulawesi Selatan. Makassar: Ininnawa.

Khaw, Nasha Rodziadi, Nazarudin Zainun, Tarmiji Masron, Zulkifli Jaafar. 1984. "Kemerosotab Kedah Tua: Mangsa Percaturan Politik Sosioekonomi Dunia Timur (Kurun ke13-14)", dalam Khoo Kay Kim, Malaysia dari Segi Sejarah. Kuala Lumpur: Persatuan Sejarah Malaysia, HIm. 52-67

Lan, Nio Joe. 2013. Peradaban Tionghoa Selayang Pandang. Jakarta: KPG.

Lip, Evelyn. 1981. Chinese Temples and Arhitecture in Singapore. National Singapore University Press.

Mahmud, M. Irfan. Mahmud, M. Irfan. 2003. Kota Kuno Palopo: Dimensi Fisik, Sosial, dan Kosmologi. Cet. 1. Makassar: Masagena Press.

2012. Pengaruh Peradaban Islam di Papua. Papua TH IV No. 2 November 2012, HIm. 27-41.

Onghokham. 2008. Anti Cina kapitalisme Cina dan Gerakan Cina: Sejarah Etnis Cina di Indonesia. Jakarta: Komunitas Bambu.

Onim, J. F. 2006. Islam dan Kristen di Tanah Papua. Bandung: Jurnal Info Media.

Prasetyo, Bagyo. 2011. "Budaya Pantai dan Pedalaman Masa Prasejarah di Papua", dalam M. Irfan Mahmud dan Erlin Novita Idje Djami (ed.), Austronesia dan Melanesia di Nusantara. Yogyakarta: Penerbit Ombak. HIm. 75-94.

Ririmase, Marlon NR. 2011. Arkeologi Kawasan Tapal Batas: Koneksitas Kepulauan Maluku dan Papua. Papua TH. III No. 1 Juni 2011.

Skinner, Stephen. 1986. Feng Shui. IImu Tata Letak Tanah dan Kehidupan Cina Kuno. Semarang: Dahana Prize.

Suryadinata, Leo. 1984. Dilema Minoritas Tionghoa. Jakarta: PT Graffiti.

Tan, Mely G. 2008. Etnis Tionghoa di Indonesia. Edisi I. Jakarta: Yayasan Obor Indonesia.

Tolla, Marlin. Migrasi Etnis Tionghoa di Kabupaten Yapen Waropen. Jurnal Papua Vol. 2 No.2/ November 2010.

Widjojo, Muridan. 2013. Pemberontakan Nuku: Persekutuan Lintas Budaya di Maluku-Papua Sekitar 1780-1810. Depok: Komunitas Bambu. 